Dear Author,

Please, note that changes made to the HTML content will be added to the article before publication, but are not reflected in this PDF.

Note also that this file should not be used for submitting corrections. 


\title{
Organotin persistence in contaminated marine sediments and porewaters: In situ degradation study using species-specific stable isotopic tracers
}

\author{
${ }_{4}^{\text {Q1 }}$ Martina Furdek ${ }^{\mathrm{a}}$, Nevenka Mikac ${ }^{\mathrm{a}}$, Maite Bueno ${ }^{\mathrm{b}}$, Emmanuel Tessier ${ }^{\mathrm{b}}$, Joana Cavalheiro ${ }^{\mathrm{b}}$, \\ Mathilde Monperrus ${ }^{\mathrm{b}, *}$ \\ 6 Q2 a Division for Marine and Environmental Research, Rudjer Boskovic Institute, Bijenicka 54, Zagreb, Croatia \\ ${ }^{\mathrm{b}}$ Laboratoire de Chimie Analytique Bio-inorganique et Environnement, Institut Pluridisciplinaire de Recherche sur l'Environnement et les Matériaux, CNRS \\ UMR 5254, Université de Pau et des Pays de l'Adour, Hélioparc Pau Pyrénées, 2, Av. P. Angot, 64053 Pau Cedex 9, France
}

\section{H I G H L I G H T S}

- Limiting step in OTC degradation in sediments is their desorption into porewater.

- TBT persistence in contaminated sediments increases in sediments rich in organic matter.

- DBT does not accumulate in sediments as degradation product of TBT.

- TBT and DBT degradation in porewaters occurs with half-lives from 2.9 to 9.2 days.

- PhTs degradation is slower than BuTs degradation in oxic porewaters.

\section{A R T I C L E I N F O}

\section{Article history:}

Received 5 September 2015

Received in revised form 1 December 2015 Accepted 20 December 2015

Available online $\mathrm{xxx}$

\section{Keywords:}

Organotin compounds

Tributyltin

Degradation kinetics

Isotopically enriched tracers

Sediments

Organic matter
G R A P H I C A L A B S T R A C T

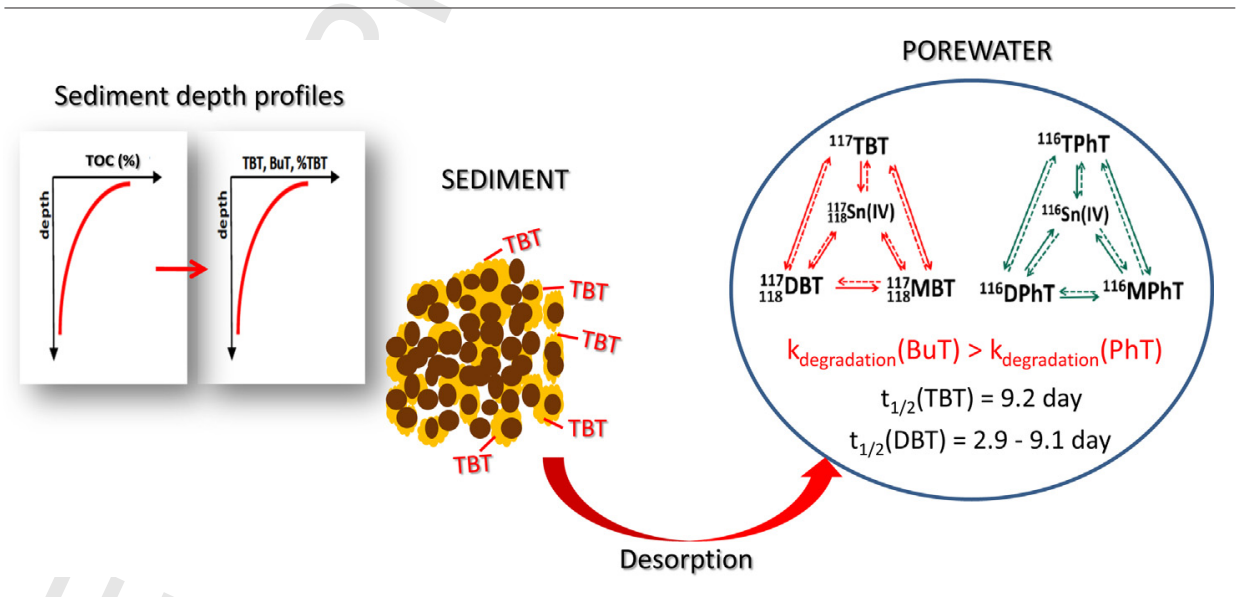

A B S T R A C T

This paper provides a comprehensive study of the persistence of butyltins and phenyltins in contaminated marine sediments and presents the first data on their degradation potentials in porewaters. The study's aim was to explain the different degradation efficiencies of organotin compounds (OTC) in contaminated sediments. The transformation processes of OTC in sediments and porewaters were investigated in a field experiment using species-specific, isotopically enriched organotin tracers. Sediment characteristics (organic carbon content and grain size) were determined to elucidate their influence on the degradation processes. The results of this study strongly suggest that a limiting step in OTC degradation in marine sediments is their desorption into porewaters because their degradation in porewaters occurs notably fast with half-lives of 9.2 days for tributyltin (TBT) in oxic porewaters and $2.9 \pm 0.1$ and $9.1 \pm 0.9$ days for dibutyltin (DBT)

\footnotetext{
* Corresponding author.

E-mail address: mathilde.monperrus@univ-pau.fr (M. Monperrus).
} 
in oxic and anoxic porewaters, respectively. By controlling the desorption process, organic matter influences the TBT degradation efficiency and consequently defines its persistence in contaminated sediments, which thus increases in sediments rich in organic matter.

(c) 2015 Published by Elsevier B.V.

\section{Introduction}

${ }_{47} \mathrm{Q}^{3}$

Tributyltin (TBT), and triphenyltin (TPhT), have found application as biocides in antifouling paints and have therefore been directly introduced into the marine environment. As TPhT is also used as pesticide in agriculture, land run off could additionally contribute to its introduction to the coastal waters. Both compounds, acting as endocrine disruptors, provoke toxic effects to various non-target marine organisms, the most adverse toxic effect being occurrence of imposex in gastropods even at very low concentrations in seawater (1-2 ng/l) [1,2]. Nowadays, TBT is declared as one of the most toxic anthropogenic pollutants in the marine environment [1]. Consequently, the use of TBT-based paints has been banned in many countries worldwide, including all of Europe, and they have been banned in Croatia since 2006. However, an overview of the existing data in recently published papers demonstrates that the marine environment is still polluted with TBT, especially in countries where the usage of TBT-based paints is not yet regulated [3]. Preliminary data on butyltin (BuTs) contamination along the Croatian Adriatic coast also showed widespread pollution with TBT ${ }_{65} \mathrm{Q}^{4}$ and suggested that those paints are still in use despite their ban [4]. Once introduced into the water column, TBT and TPhT are subjected to biotic (degradation governed by microbial activity) and abiotic degradation with half-lives of several days to weeks [1,2,5,6]. Abiotic degradation includes photodegradation (i.e., degradation by UV irradiation), thermal and chemical degradation. Among all abiotic degradation mechanisms, photolysis has the most important role in BuTs and PhTs degradation in environmental compartments where light is available (water column and the thin surface sediment layer in shallow waters) [7,8]. Both TBT and $\mathrm{PhT}$ are stable up to $200^{\circ} \mathrm{C}[9]$, and thus are not prone to thermal degradation under environmental conditions, while little is known about chemical degradation of OTC in natural environment, especially aquatic sediments. Because TBT and TPhT have both a high affinity for adsorption onto particulate matter $(\log \mathrm{Kd}>3.5[10,11])$, they accumulate in sediments where their degradation occurs at considerably slower rates, with half-lives of several years to decades $[1,2,12,13]$. Due to the persistence of BuTs and PhTs in sediments and their possible desorption back into the water column $[10,14,15]$, contaminated sediments represent a long-term source of pollution. Therefore, TBT and TPhT degradation in sediments can be considered to control the overall persistence of BuTs and PhTs in the marine environment. Since their degradation products (di- and mono-butyl and phenyl derivatives) are far less toxic than initial trisubstituted compounds [16], degradation can be considered as a form of sediment remediation.

During the past decades, numerous papers regarding TBT degradation in the marine environment have been published. Most of them have been macrocosm $[17,18]$ or microcosm $[19,20]$ experiments or other laboratory setups in which complex environmental conditions could never be completely simulated [21,22]. The studies performed in situ were primarily based on the modelling of TBT concentration reduction with sediment depth $[12,23,24,25]$. This approach has several disadvantages because it assumes undisturbed sediment and continuous input, whereas the sedimentation rate has to be known. Additionally, it does not provide the complete interpretation of the degradation mechanisms because the kinetics of each degradation step cannot be determined. There- fore, more data are required to establish a better understanding of butyltin degradation processes in sediments, especially those that occur under anoxic conditions; meanwhile, the degradation of phenyltins (PhTs) in sediments is rarely experimentally studied and still not well explained.

Sediment characteristics such as organic matter and grain size have been demonstrated many times to have an influence on the adsorption of TBT onto sediment particles $[10,11,26]$, but their role in BuT degradation in the sediment remains unclear. By controlling the adsorption of TBT, organic matter is considered to define its bioavailability because only the TBT present in porewater is believed to be available to microorganisms and actually prone to biodegradation [27]. In spite of this, OTC degradation in porewater has not been studied thus far while only a few papers have reported the levels of BuTs in porewater $[13,10,28]$.

This paper provides a comprehensive study of the persistence of BuTs and PhTs in contaminated marine sediments. The aim was to explain the apparent, different TBT degradation efficiencies in different sediments and to verify whether the degradation of BuTs and PhTs in sediments occurs mainly in porewater. The study was performed as follows: (i) TBT persistence in various types of contaminated sediments was assessed by a determination of butyltin depth profiles in sediment cores; (ii) sediment characteristics (organic carbon and grain size) were determined to study their influence on the TBT degradation efficiency; and (iii) butyltin and PhT degradation processes in sediments and porewaters were studied using species-specific, isotopically enriched tin tracers $\left({ }^{117} \mathrm{Sn}\right.$-enriched TBT $\left({ }^{117} \mathrm{TBT}\right),{ }^{118} \mathrm{Sn}$-enriched DBT ( $\left.{ }^{118} \mathrm{DBT}\right),{ }^{116} \mathrm{Sn}$-enriched TPhT ( $\left.{ }^{116} \mathrm{TPhT}\right)$ ). This multi-isotopic labeling methodology enables any degradation route to be followed individually, despite the simultaneous formation and degradation processes of certain compounds, thereby enabling the determination of the kinetics of each degradation step and consequently helping to characterize the overall degradation mechanism.

\section{Materials and methods}

\subsection{Sediment sampling}

The sediment cores were collected in 2011 at 8 locations (M1-M8), mainly marinas, located along the Croatian Adriatic coast, while the incubation experiments were performed in 2012 using sediments from the locations M1, M2 and M6 (Fig. S1, Supplementary information). The marinas differed in size based on the number of berths that varied from 200 to 800 (M1-350; M2-190; M3-800; M4-450; M5-300; M6-city port; M7-200; and M8-630). The depth of the water column at the sampling locations varied between 2 and $35 \mathrm{~m}$ (M1-15 m; M2-2 m; M3-35 m; M4-5 m; M5-6 m; M6-144 m; M7-6 m; and M8-3 m). The sampling was performed using a UWITEC gravity corer. The sediment cores (M1-M8) used for the determination of BuTs and sediment characteristics were frozen after sampling, cut in the laboratory into $2 \mathrm{~cm}$ layers, freeze-dried and homogenized by milling (except for grain size analysis). The samples were kept at $-20^{\circ} \mathrm{C}$, and the OTCs were measured within 3 months. The sediment cores used for the incubation experiment were cut into layers, spiked and incubated in the field within $3 \mathrm{~h}$ after sampling. Additional cores were taken to 

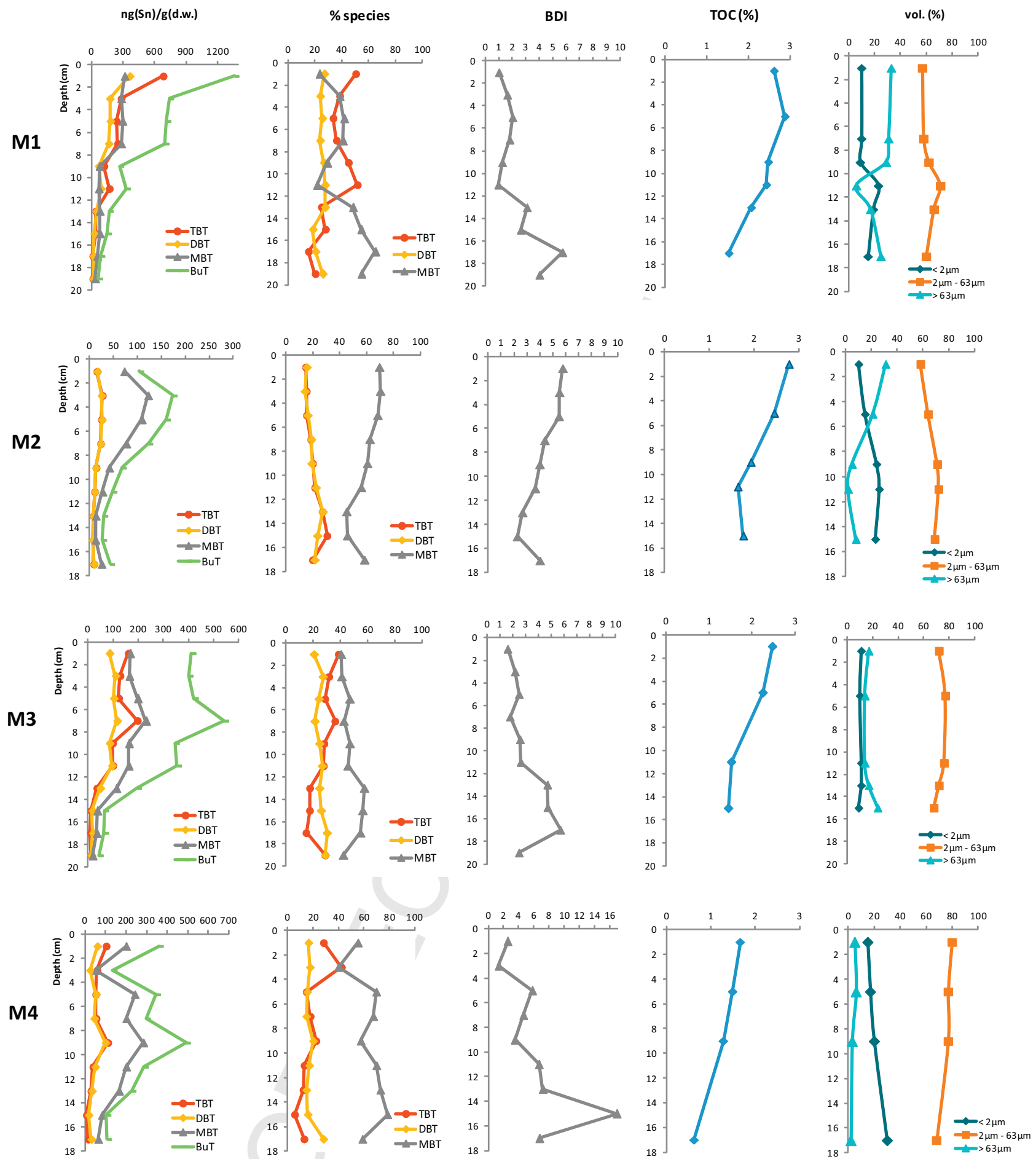

Fig. 1. Depth distributions of butyltin concentrations, percentage of each species towards $\Sigma$ BuT, BDI index, TOC and granulometric composition in sediment cores M1-M4 (first group).

determine the OTC depth profiles in porewaters and calculate the $\mathrm{Kd}$ values. Porewaters were isolated from the sediments immediately after sampling by centrifugation and filtered through a $0.45 \mu \mathrm{m}$-size acetate filter. To determine the oxic/anoxic conditions in sediments, the redox potential (Eh) was measured by InLab Redox electrode.

\subsection{OTC determination in sediments}

The extraction of OTC (BuTs and PhTs) from the sediments was performed by the method developed by Milivojevič Nemanič et al. [29]. Briefly, OTCs were extracted from the sediment by acetic acid and ultrasonic stirring. Then, simultaneous derivatization with $\mathrm{NaBEt}_{4}$ and extraction into hexane were performed in a sodium 

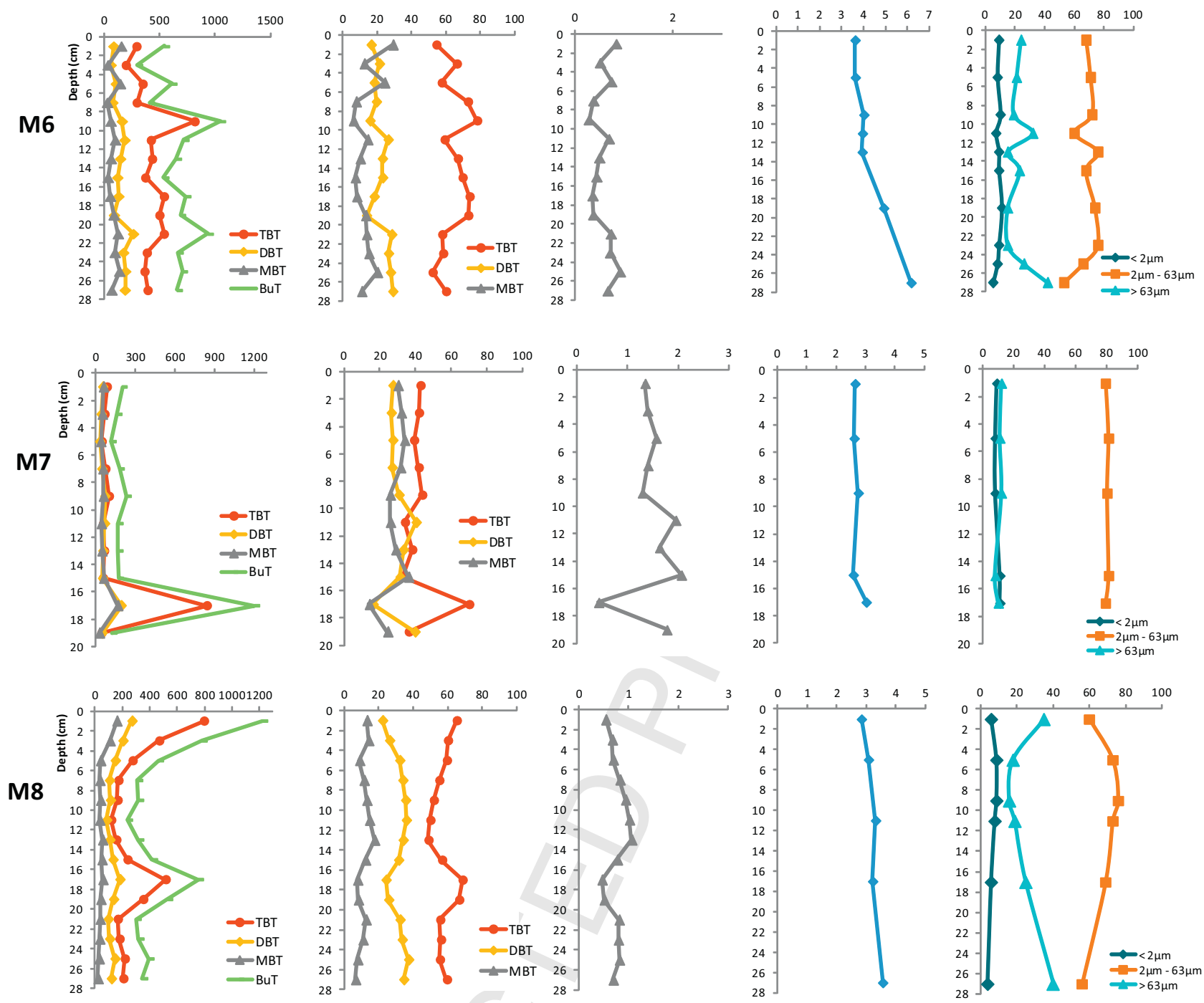

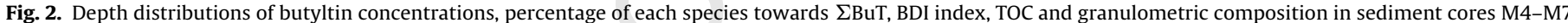
(second group).

acetate-acetic acid buffer ( $\mathrm{pH} 4.8$ ). The detection of OTCs was performed on a gas chromatograph (GC, Varian CP3800) with a pulsed flame photometric detector (PFPD, Varian) [4]. The quality control was performed by the analysis of standard reference material certified for BuTs in the marine sediments (PACS 2, Ottawa, Canada), or by spiking the sample with phenyltins standard solution of known concentrations. The limits of method detection ranged from 1.5 to $6.1 \mathrm{ng}(\mathrm{Sn}) \mathrm{g}^{-1}$ (d.w.).

\subsection{Sediment and porewater incubation experiments}

\subsubsection{Sediment incubation}

The surface sediment layers $(0-2 \mathrm{~cm})$ from three locations (M1, M2 and M6) and deeper sediment layers $(10-12 \mathrm{~cm})$ from two locations (M1 and M2) were incubated following the experimental procedure previously described by Rodriguez-Gonzalez et al. [5]. The slurry was prepared by mixing approximately $4 \mathrm{~g}$ of surface sediments (Eh $=-50-(-100) \mathrm{mV}$ ) with $4 \mathrm{ml}$ of the oxic overlaying seawater $(E h=136-288 \mathrm{mV})$ in a $40 \mathrm{ml}$ glass vial. The spiking solution containing ${ }^{117} \mathrm{TBT},{ }^{118} \mathrm{DBT}$ and ${ }^{116} \mathrm{TPhT}$ was added to obtain the final concentrations of approximately 200, 200 and $20 \mathrm{ng}$ $(\mathrm{Sn}) / \mathrm{g}$ (d.w.), respectively. Because the slurry consisted of suboxic sediments and oxic waters while the spiking was performed in the presence of oxygen, these samples were termed as oxic sediments in which OTC degradation in oxic conditions was studied. Deeper anoxic sediment layers $(\mathrm{Eh}=-292-(-397) \mathrm{mV}$ ) were mixed with seawater from which dissolved oxygen was removed by purging with $\mathrm{N}_{2}$; meanwhile, the whole procedure and sample manipulation were performed in a glove bag under a nitrogen atmosphere. These samples were considered as anoxic sediments in which the degradation in anoxic conditions was investigated. The vials with the spiked sediments were incubated directly in the field (dark, $\left.19-21^{\circ} \mathrm{C}\right)$ for one $(t=24 \mathrm{~h})$ and three $(t=72 \mathrm{~h})$ days. Control incubations $(t=0)$ were performed by freezing the samples in liquid nitrogen immediately after the spike addition. All incubations were performed in triplicate.

\subsubsection{Porewater incubation}

Porewaters were isolated from two sediment layers (0-2 cm-oxic porewater; $10-12 \mathrm{~cm}$-anoxic porewater) of sediment cores M1 and M2. Isolated porewaters $(10-15 \mathrm{ml})$ from each location were spiked and incubated in the same manner described for the sediments. The final concentrations of the added, isotopically enriched tin tracers were approximately 2, 2 and $0.2 \mu \mathrm{g}(\mathrm{Sn}) / 1$ for ${ }^{117} \mathrm{TBT},{ }^{118} \mathrm{DBT}$ and ${ }^{116} \mathrm{TPhT}$, respectively. The control incubations $(t=0)$ were performed by adding high 


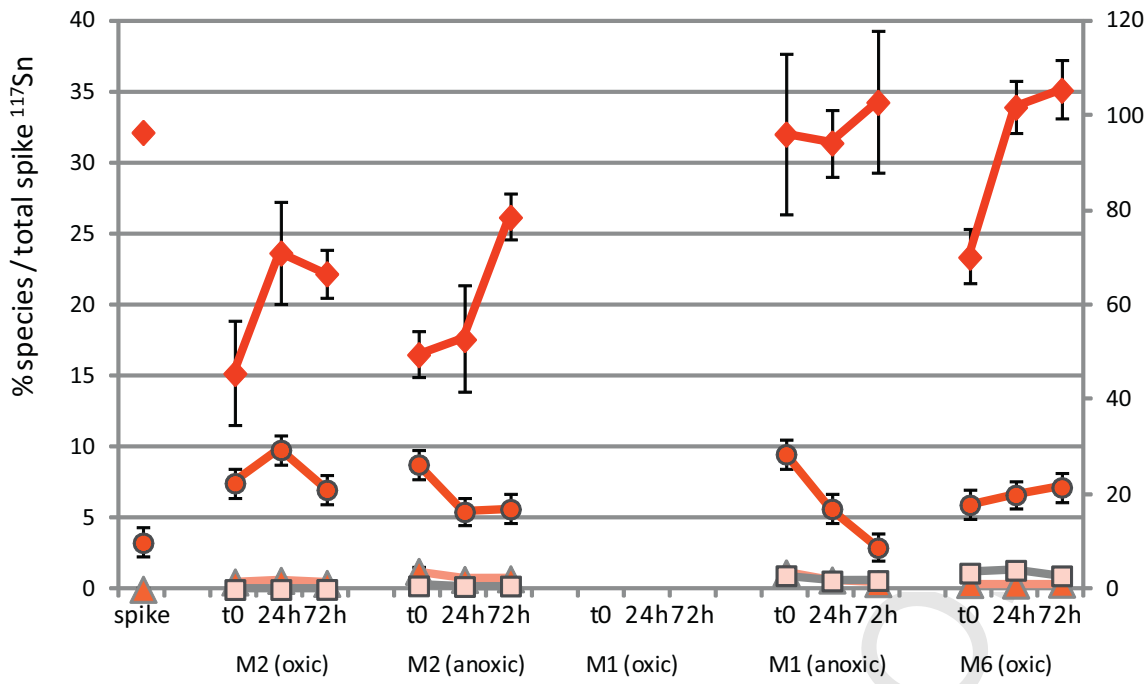

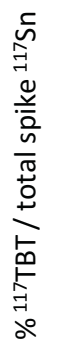

(A)

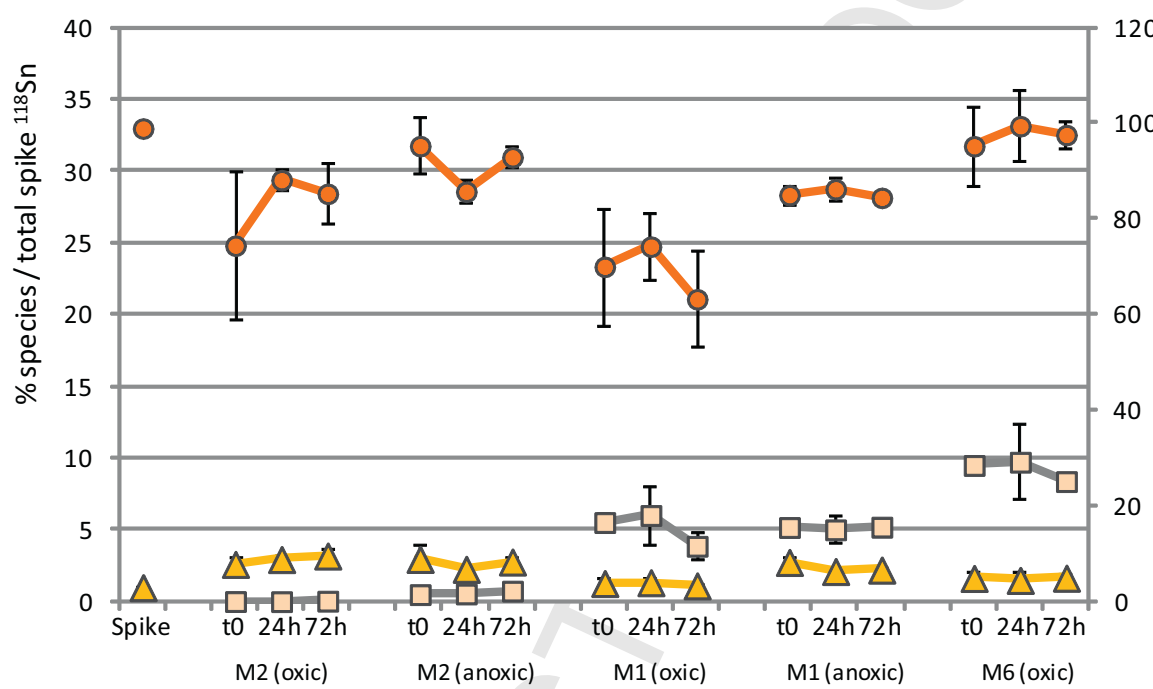

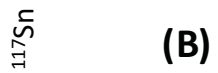

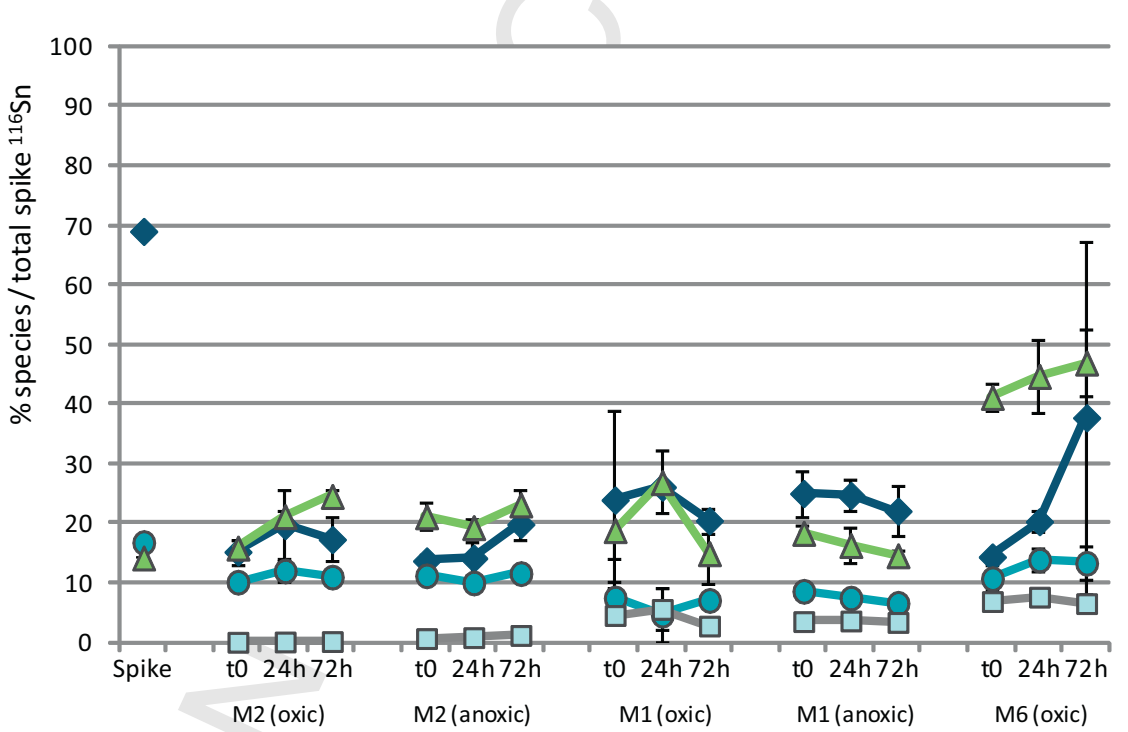

(C)

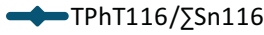

-DPPhT116/ $\mathrm{Sn} 116$

$\triangle \mathrm{MPhT} 116 / \Sigma \mathrm{Sn} 116$

$\square-\operatorname{Sn}(\mathrm{IV}) 116 / \Sigma \mathrm{Sn} 116$

Fig. 3. Formation and degradation yields of (A) ${ }^{117} \mathrm{Sn}$-enriched butyltin species, (B) ${ }^{118} \mathrm{Sn}$-enriched butyltin species and (C) ${ }^{116}$ Sn-enriched phenyltin species in oxic and anoxic incubated sediments. The uncertainty values correspond to $1 \mathrm{~s}$ standard deviation of three independent incubation experiments.

Please cite this article in press as: M. Furdek, et al., Organotin persistence in contaminated marine sediments and porewaters: In situ degradation study using species-specific stable isotopic tracers, J. Hazard. Mater. (2015), http://dx.doi.org/10.1016/j.jhazmat.2015.12.037 

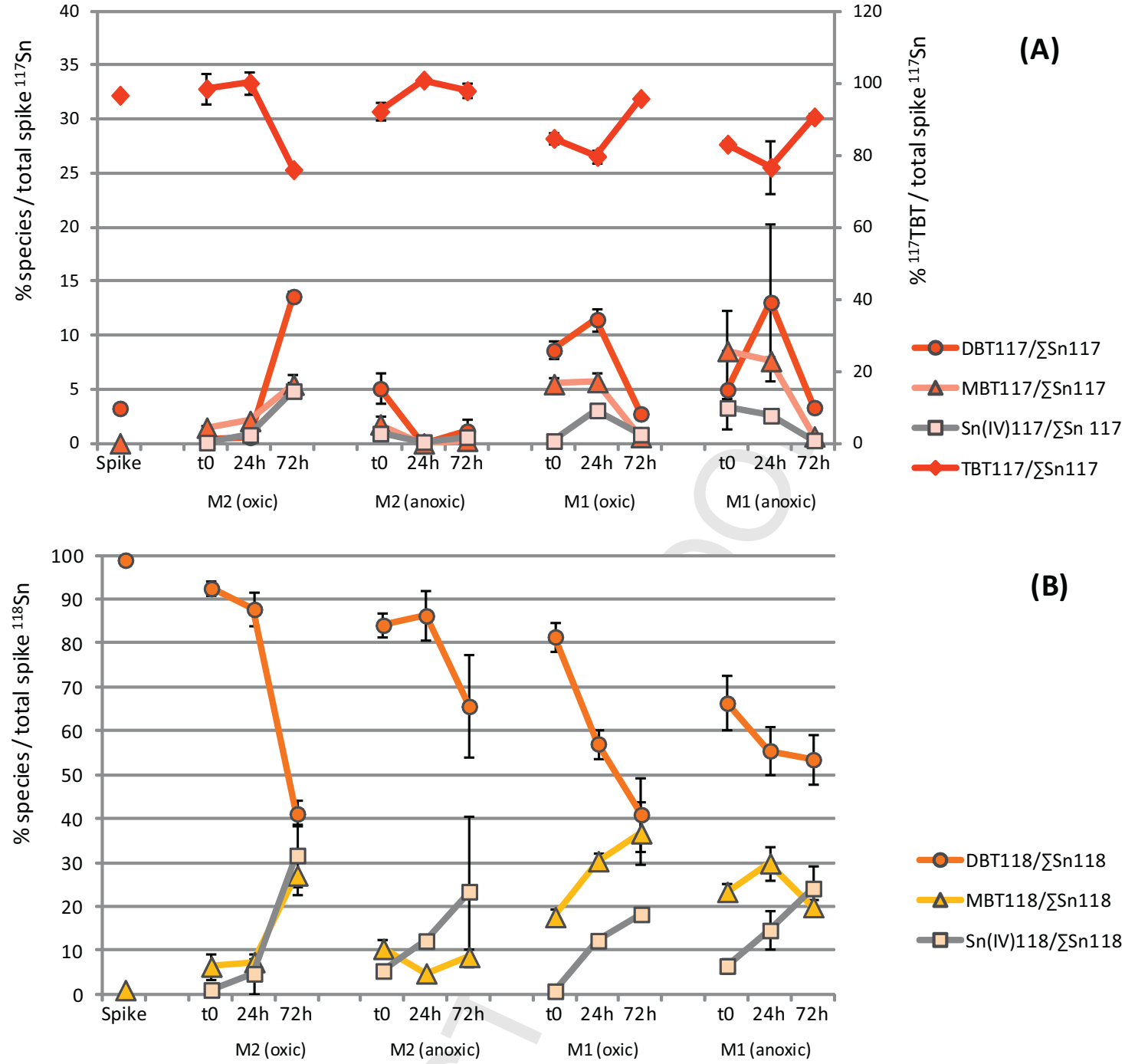

(B)

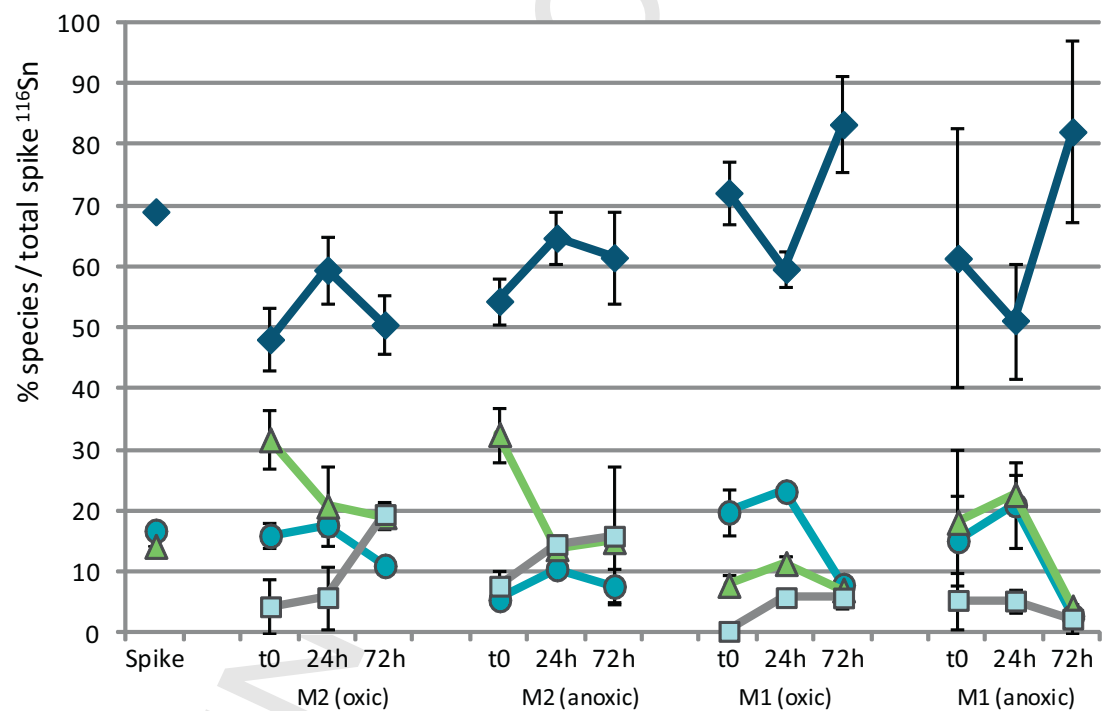

(C)

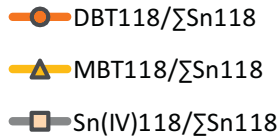

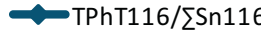

-O-DPhT116/ $\mathrm{Sn} 116$

$\triangle \mathrm{MPhT} 116 / \Sigma \mathrm{Sn} 116$

$-\square-\operatorname{Sn}(\mathrm{IV}) 116 / \Sigma \mathrm{Sn} 116$

Fig. 4. Formation and degradation yields of $(A){ }^{117}$ Sn-enriched butyltin species, (B) ${ }^{118}$ Sn-enriched butyltin species and (C) ${ }^{116}$ Sn-enriched phenyltin species in oxic and anoxic incubated porewaters. The uncertainty values correspond to $1 \mathrm{~s}$ standard deviation of three independent incubation experiments.

Please cite this article in press as: M. Furdek, et al., Organotin persistence in contaminated marine sediments and porewaters: In situ degradation study using species-specific stable isotopic tracers, J. Hazard. Mater. (2015), http://dx.doi.org/10.1016/j.jhazmat.2015.12.037 
purity $\mathrm{HNO}_{3}(65 \%, \mathrm{v} / \mathrm{v})$ immediately after the spike addition. All incubations were performed in triplicate.

\subsection{Determination of OTC transformation yields in sediment and porewater}

The measurement of the isotopic composition of OTCs in the incubated porewater and sediment samples was performed by GC (Trace GC, Thermo Fisher) coupled with inductively coupled plasma mass spectrometry (ICPMS, XSeries 2, Thermo Fisher) as described in detail elsewhere $[5,30]$. Briefly, the sediment samples were subjected to open microwave extraction in a mixture of acetic acid and methanol (3:1) followed by ethylation with $\mathrm{NaBEt}_{4}$ and extraction into isooctane by shaking. In the case of porewaters, only the second step (derivatization and extraction to isooctane) was required. Because the incubation was performed with isotopically enriched tracers, the quantification of OTCs was performed by reverse isotope dilution analysis by adding an adequate amount of natural abundance standards. The final OTC concentrations derived from each isotopic tracer at the end of incubation were determined by a mathematical approach based on the deconvolution of isotopic patterns, as previously developed and precisely described by Rodríguez-González et al. [5]. This multi-isotopic labeling methodology enables the determination of the degradation kinetics of each compound under study by following the degradation route of each isotopic tracer as shown in the equation (1). The half-lives $\left(t_{1 / 2}\right)$ were calculated from the transformation rate constants determined from the degradation yields assuming first-order transformation reactions.
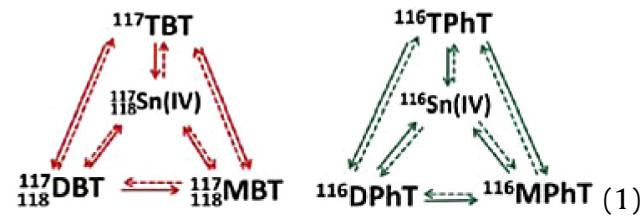

\subsection{Determination of sediment characteristics}

Total organic carbon (TOC) analyses were performed by a high-temperature catalytic oxydation method with non-dispersive infrared (NDIR) detection on a TOC- $\mathrm{V}_{\mathrm{CPH}}$ Shimadzu carbon analyzer. The inorganic carbonate fraction was removed with $2 \mathrm{M} \mathrm{HCl}$ followed by drying at $50^{\circ} \mathrm{C}$ overnight. The grain size analysis was performed using a laser diffraction particle size analyzer LS 13320 (Beckman-Coulter).

\section{Results and discussion}

\subsection{Butyltin depth distributions}

OTCs were found in all investigated sediment cores with the total butyltin concentrations $\left(\sum \mathrm{BuT}=\mathrm{TBT}+\mathrm{DBT}+\mathrm{MBT}\right)$ ranging from 30.1 to 2059.9 (average $553.1 \pm 433.9) n g(S n) / g(d . w$.$) . The$ butyltin depth distributions, as well as the percentage of each species, are shown in Figs. 1 and 2. The level of pollution in marinas varied significantly but was not related to the size of marina, number of berths, or the sampling depth. Phenyltins, mainly TPhT and MPhT (monophenyltin), were detected in several layers at all locations (except M7) at concentrations ranging from 12.4 to 313.6 (average $98.6 \pm 90.7) \mathrm{ng}(\mathrm{Sn}) / \mathrm{g}($ d.w.) (data not shown). Their presence was associated with the layers containing the highest butyltin concentrations, while their concentrations were always 2-20 times lower than those of BuTs. This is in accordance with a much lower use of TPhT in antifouling paints. Generally, the level of OTC contamination in sediments from the Croatian Adriatic Coast can be evaluated as similar or even higher than those recently reported in the literature for coastal sediments [6,31,32].

The butyltin depth profiles from different locations (Figs. 1 and 2) do not follow the same depth pattern: at some locations both the TBT and total butyltin concentrations decrease while for others they do not change with depth. The same observations were also reported in the literature and discussed as a consequence of different degradation efficiencies, the desorption of BuTs from sediments or different butyltin inputs over time [12,24,28,33]. Some authors have also discussed that in highly polluted sediments TBT could have a biocide effect on bacterial activity, leading to its slower degradation [6,33]. However, relatively efficient TBT degradation was reported in laboratory studies under very high TBT concentrations [34]. Because all sediments were collected in marinas constructed before 1980 , we assume that the most probable explanation for the different butyltin depth patterns is different TBT degradation efficiencies in these sediments. To verify this assumption, the level of TBT degradation in each sediment core was evaluated using the Butyl Degradation Index (BDI). This index is considered a reliable tool for assessments of TBT degradation efficiency and is defined as the concentration ratio of TBT and its degradation products $(\mathrm{BDI}=(\mathrm{MBT}+\mathrm{DBT}) / \mathrm{TBT})[35]$. BDI values less than 1 indicate that TBT prevails over its degradation products, thus indicating poor TBT degradation or recent input, while BDI values higher than 1 imply efficient degradation or the long-term presence of TBT in sediments. On the basis of calculated BDI values (higher or lesser than 1) and different TBT and butyltin depth profiles, the investigated sediments were classified into two groups: first group (Fig. 1) and second group (Fig. 2).

The first group includes the sediments from locations M1-M4, where the highest TBT and butyltin concentrations were detected mainly in the surface layers and followed by their noticeable decline with depth (Fig. 1). The proportion of TBT within the total BuTs gradually decreased from 40 to $60 \%$ in the surface layers to less than $10 \%$ in the bottom layers (Fig. 1). At the same time, the proportion of MBT increased with depth, although its accumulation in the deeper layers was not detected. We may speculate that MBT desorbs from sediments to the overlaying water, or it degrades to inorganic tin. The former is supported by several research papers stating that MBT desorbs from sediments more readily than other BuTs as a result of its lower hydrophobicity $[12,36]$. We assume that in the sediments from the first group efficient degradation occurs, which is supported by the BDI profiles because the BDI values were approximately 1 in the surface layers and progressively increased with depth to 16.9 (Fig. 1). Fig. 2 shows the butyltin concentration profiles of the sediments from locations M5-M8, which are classified as the second group. In these sediments the TBT and butyltin concentrations in the deeper layers were similar to those at the surface, showing no decline with depth. The proportion of TBT (Fig. 2) did not fall below $40 \%$ throughout the entire core at all locations, while the BDI values (Fig. 2) were less than 1 in all layers (or 1.5 at location M2). These observations led to the assumption that in these sediments weak degradation occurs, which is further supported by the fact that the higher TBT concentrations detected at certain depths (M5: 4-6 cm; M7: 16-18 cm; M8: 16-18 cm) correspond to a higher proportion of TBT. It is interesting to note that in all sediment cores, regardless of group, the proportion of DBT was 20-30\% throughout the entire core (Figs. 1 and 2). This result indicates that DBT does not accumulate in sediments as an intermediate product in TBT degradation.

\subsection{Sediment characteristics as parameters controlling TBT degradation efficiency}

The results presented above strongly suggest that sediments belonging to a particular group have similar TBT degradation rates, 
Table 1

Transformation rate constants of isotopically enriched butyltin and PhT species in oxic and anoxic porewaters from sediment cores M1 and M2.

\begin{tabular}{|c|c|c|c|c|}
\hline & \multicolumn{4}{|c|}{ Transformation rate constants $\left(\right.$ day $\left.^{-1}\right)$} \\
\hline & \multicolumn{2}{|l|}{ Oxic $(0-2 \mathrm{~cm})$} & \multicolumn{2}{|c|}{ Anoxic $(10-12 \mathrm{~cm})$} \\
\hline & M2 & M1 & M2 & M1 \\
\hline${ }^{117}$ TBT degradation & $0.076 \pm 0.012$ & $*$ & - & - \\
\hline${ }^{117} \mathrm{DBT}$ formation & $1.096 \pm 0.009$ & $*$ & - & - \\
\hline${ }^{117} \mathrm{MBT}$ formation & $0.426 \pm 0.028$ & - & - & - \\
\hline${ }^{117} \mathrm{Sn}(\mathrm{IV})$ formation & $1.374 \pm 0.121$ & $*$ & - & - \\
\hline${ }^{118}$ DBT degradation & $0.248 \pm 0.020$ & $0.239 \pm 0.052$ & $0.072 \pm 0.038$ & $0.083 \pm 0.005$ \\
\hline${ }^{118} \mathrm{MBT}$ formation & $0.449 \pm 0.130$ & $*$ & - & * \\
\hline${ }^{118} \mathrm{Sn}(\mathrm{IV})$ formation & $1.182 \pm 0.184$ & $1.298 \pm 0.238$ & $0.525 \pm 0.055$ & $0.476 \pm 0.003$ \\
\hline${ }^{116} \mathrm{TPhT}$ degradation & - & $*$ & - & - \\
\hline${ }^{116} \mathrm{DPhT}$ formation & $*$ & $*$ & - & - \\
\hline${ }^{116} \mathrm{MPhT}$ formation & $*$ & $*$ & $*$ & - \\
\hline${ }^{116} \mathrm{Sn}(\mathrm{IV})$ formation & $0.482 \pm 0.053$ & $*$ & $*$ & - \\
\hline
\end{tabular}

which differ between those two groups. The following aim was to evaluate if sediment characteristics may be responsible for different TBT degradation potentials in two defined groups of sediments. The results of the TOC analyses are shown in Figs. 1 and 2. The values ranged from $0.62 \%$ to $6.15 \%$. When comparing two previously defined sediment groups concerning TOC depth distributions, two observations could be noted: (i) sediments from the second group have significantly higher $(p<0.05)$ TOC values with average values of $3.70 \pm 0.86 \%$, which is nearly 2 times higher than in the first group (average is $1.96 \pm 0.59 \%$ ), and (ii) the TOC depth distribution follows the same pattern as the TBT and total butyltin concentrations in all sediment cores. Therefore, the decrease in TOC with depth is observed in sediments from the locations M1-M4 (first group, Fig. 1), whereas in the sediments from M5-M8 (second group, Fig. 2) the TOC did not change with depth or even increased. Although many published papers have demonstrated that TBT is adsorbed onto sediments preferably by binding with organic matter $[10,11]$, contradictory results on the relationship between TBT levels and TOC in natural marine sediments can be found. Some authors stated that significant correlations exist between the TOC and TBT concentration [3,37-39], while others found little or no correlation [13,32]. However, most of these data refer only to surface sediments; thus, they do not provide any information about the influence of organic matter on the TBT degradation over time. In our study, a statistically significant correlation was found between the TBT concentrations and TOC (Pearson, $r=0.63, p<0.05$ ) when all samples (all layers of all sediment cores) were considered. An even stronger correlation was found between the TBT proportion and TOC (Pearson, $r=0.83, p<0.05$ ) as well as between BDI and TOC (Pearson, $r=-0.87, p<0.05$ ), thus leading to the assumption that organic matter strongly affects the degradation process of TBT in sediments in addition to adsorption. When comparing the TBT concentration and TOC in each sediment core, apart from their similar depth patterns, in some cases even statistically significant correlations (Pearson, $p<0.05$ ) were found (M1-M3, M7). Furthermore, strong and statistically significant correlations (Pearson, $p<0.05$ ) between the TBT and DBT, DBT and MBT, and TBT and MBT concentrations were found in all sediment cores belonging to the first group (M1-M4). This further supports the assumption that in these sediments efficient TBT degradation occurs. On the other hand, the correlations between TBT and its degradation products were not found in any of the sediment cores from the second group (M5-M8), additionally supporting poor degradation in these sediments. Under conditions of very slow TBT degradation, the degradation products, which are less hydrophobic and more mobile, have time to diffuse to other sediment layers, thus resulting in the absence of correlation with TBT. From the foregoing discussion it follows that TBT degradation is much more efficient in sediments with lower amounts of organic matter (first group).
Therefore, it can be concluded that organic matter, in addition to its crucial role as a TBT sorbent in sediments, also has an important influence on the TBT degradation efficiency and its persistence in contaminated sediments.

Organic matter could influence the TBT persistence in sediments in two different ways. The first is the role of organic matter in redox conditions in sediments and consequently in the composition of the present microbial community. The second is the major influence of organic matter on TBT adsorption onto sediments $[10,11,26]$. Indeed, if the TOC is higher than $0.5 \%$, the sorption of TBT onto mineral phases is considered to be negligible [10,11]. By controlling the TBT adsorption, organic matter regulates TBT partitioning in the sediment-porewater system. Because only the compounds present in porewater are considered to be bioavailable to microorganisms [40], the organic matter in sediments could influence the degradation of TBT by defining its bioavailable fraction in porewater. Furthermore, once present in the porewater, TBT can migrate from deeper to surface layers, where much more efficient degradation under oxic conditions occurs [6].

The results of the grain size analysis (Figs. 1 and 2) showed that the clay fraction $(<2 \mu \mathrm{m})$ ranged from $5 \%$ to $39 \%$ while the $<63 \mu \mathrm{m}$ fraction varied between $52 \%$ and $98 \%$. The grain size distributions generally showed little variations with depth and did not follow the same depth patterns as the TBT concentrations and TOC (Figs. 1 and 2). Grain size can indirectly influence TBT adsorption by defining the amount of adsorbed organic matter because it is well established that fine fractions adsorb more organic molecules $[32,41]$. Consequently, some authors have demonstrated that sediments with a higher proportion of fine fraction $(<63 \mu \mathrm{m})$ adsorb more TBT $[3,38,39]$; however, contrasting results, i.e., showing no correlation, can also be found in the literature [32]. In our study the correlation between TOC and fine fraction $(<2 \mu \mathrm{m}$ or $<63 \mu \mathrm{m})$ was not observed; thus, the results obtained do not allow us to evaluate the impact of grain size on TBT persistence in sediments either directly or indirectly through defining the amount of the adsorbed organic matter.

Based on our data we can postulate that TBT degradation occurs primarily in porewater, while organic matter influences the degradation process by regulating its concentration in porewater. To elucidate this hypothesis, the transformations of BuTs and PhTs in the sediments and porewaters were studied using speciesspecific, isotopically enriched tin tracers, namely ${ }^{117} \mathrm{TBT},{ }^{118} \mathrm{DBT}$ and ${ }^{116}$ TPhT.

\subsection{Butyltin and phenyltin transformations in sediments and porewaters}

The experiment consisted of the incubation of spiked surface (oxic) and bottom (anoxic) sediments and porewaters from three 


\section{M2}

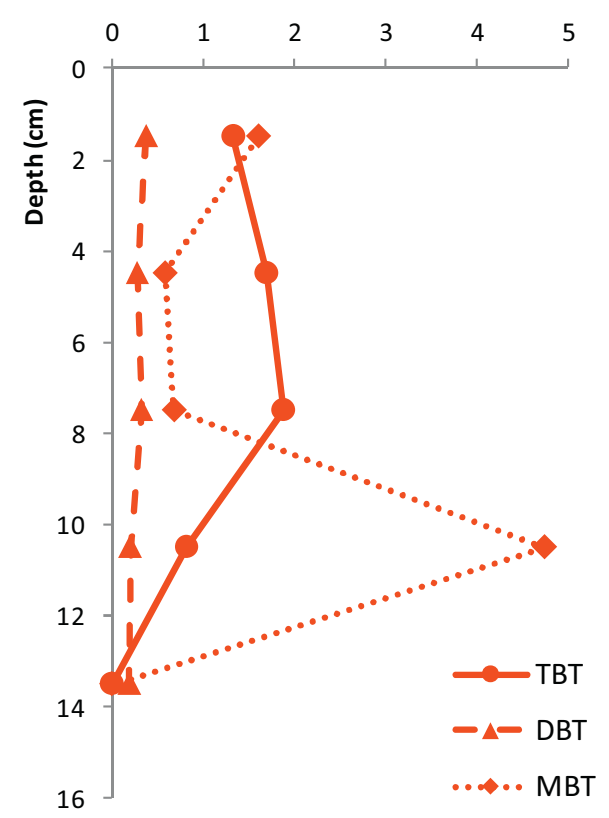

M6

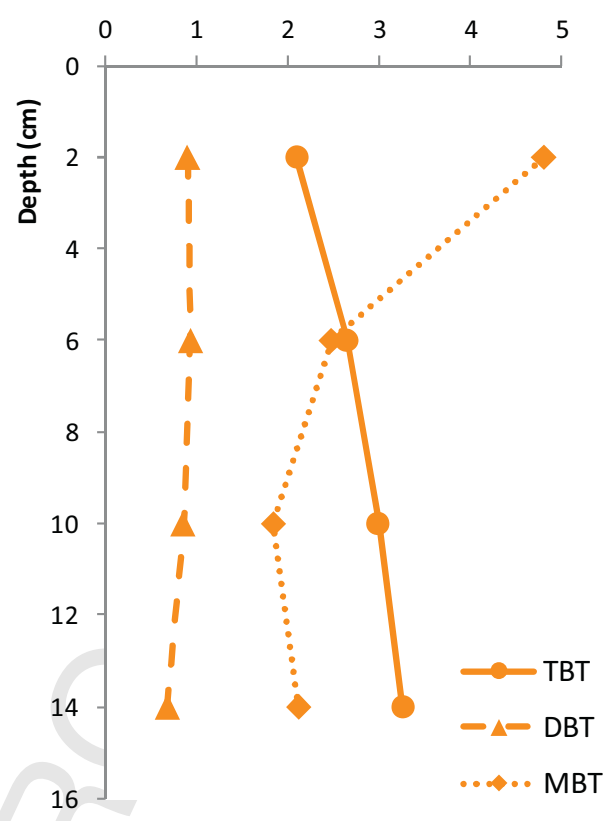

Fig. 5. Butyltin depth distributions in porewater from (A) location M2 (first group) and (B) location M6 (second group).

different locations (M1, M2 and M6). The transformation processes of ${ }^{117} \mathrm{TBT},{ }^{118} \mathrm{DBT}$ and ${ }^{116} \mathrm{TPhT}$ observed in the spiked samples during three days of incubation are presented in Figs. 3 and 4. The results are presented as the degradation and formation yields of each compound at a certain incubation time, while the yields are expressed as percentage of species enriched with a specific isotope towards the total amount of spiked specific, isotopically enriched tracers. Obtained standard deviations mostly represent the environmental variability between three independant incubations, rather than originated from the mathematical and analytical methodologies, as all samples were analyzed in triplicate and the precision obtained were always lower than $3 \%$ relative standard deviation (RSD). As seen in Fig. 3a, b, and c, the degradation of ${ }^{117}$ TBT, ${ }^{118} \mathrm{DBT}$ or ${ }^{116} \mathrm{TPhT}$ was not observed in any of the incubated sediments. Only a low ${ }^{117} \mathrm{DBT}$ degradation could be observed under anoxic conditions. However, neither ${ }^{117}$ MBT nor ${ }^{117}$ Sn were formed, and no ${ }^{118}$ DBT degradation was simultaneously observed; thus, the DBT degradation potential in the sediment cannot be confirmed. Clearly, the incubation period of three days was too short to observe some degradation in the sediments. The duration of the incubation was set considering that the environmental conditions, namely the oxygen level and microbial activity, could be disturbed for longer incubation times. The selection of the dura-

Table 2

Sediment-porewater distribution coefficients (Kd ( $1 / \mathrm{kg}))$.

\begin{tabular}{lcllll}
\hline & & & \multicolumn{2}{l}{ Log Kd } \\
\cline { 4 - 6 } Sediment core & depth $(\mathrm{cm})$ & TOC $(\%)$ & TBT & DBT & MBT \\
\hline M2 & $0-3$ & 2.91 & 4.63 & 4.52 & 4.55 \\
& $3-6$ & 2.45 & 4.33 & 4.67 & 4.85 \\
& $6-9$ & 2.19 & 4.08 & 4.71 & 4.59 \\
& $9-12$ & 1.64 & 4.05 & 4.56 & 3.30 \\
M6 & $12-15$ & 1.71 & $/$ & 4.34 & $/$ \\
& $0-4$ & 3.51 & 5.09 & 4.64 & 4.21 \\
& $4-8$ & 3.62 & 5.05 & 4.81 & 4.44 \\
& $8-12$ & 4.01 & 5.01 & 4.68 & 4.62 \\
& $12-16$ & 3.92 & 5.07 & 4.78 & 4.45
\end{tabular}

tion of the incubation experiment is not a simple task and should be established considering the ability of the method to detect transformations. However, previous work has shown that incubation periods of 1 and 7 days allowed detection of low and similar degradation yields for butyltin compounds [5]. Given unidirectional and low degradation extents of butyltins in sediments, longer incubation duration could be effectively more suitable. It should be mentioned that the recoveries for ${ }^{117} \mathrm{TBT}$ in the control incubation $(t=0)$ were low in 3 out of 4 samples (Fig. 3a), leading to difficult interpretation for these data. This could be a consequence of the lack of equilibrium between the added spike and sediment particles in the control incubation samples (which were frozen immediately after the spike addition), resulting in some losses of ${ }^{117}$ TBT during the sample manipulation.

However, the applied experimental set up enabled us to evaluate the degradation of OTCs in the porewaters, which was the major focus of our experiments, since there are no studies on this subject in the literature. The degradation of ${ }^{117}$ TBT was observed in surface oxic porewaters from both locations (M1 and M2) but not observed in any of the anoxic porewaters (Fig. 4a). In the oxic porewater M2 approximately $22 \%$ of ${ }^{117}$ TBT was degraded while the formation of ${ }^{117} \mathrm{DBT}(13 \%),{ }^{117} \mathrm{MBT}(4 \%)$ and inorganic ${ }^{117} \mathrm{Sn}$ (5\%) was detected. In the surface porewater M1 ${ }^{117}$ TBT degradation was observed only after 1 day, whereas after three days ${ }^{117}$ TBT seemed to increase. This appeared due to the decrease in the total amount of detected ${ }^{117} \mathrm{Sn}\left(\sum{ }^{117} \mathrm{Sn}={ }^{117} \mathrm{TBT}+{ }^{117} \mathrm{DBT}+{ }^{117} \mathrm{MBT}+{ }^{117} \mathrm{Sn}\right)$, which could be a consequence of some losses due to the adsorption of species onto the vials or some suspended particles left in the porewater.

The degradation of ${ }^{118}$ DBT to inorganic ${ }^{118} \mathrm{Sn}$ was observed in both oxic and anoxic porewaters (M1 and M2) (Fig. 4b). In porewater M2 $51 \%$ of the ${ }^{118}$ DBT was degraded after three days, while $21 \%$ of the ${ }^{118} \mathrm{MBT}$ and $37 \%$ of the ${ }^{118} \mathrm{Sn}$ were formed. In oxic porewater M1 the degradation of $40 \%$ of the ${ }^{118}$ DBT was detected along with the formation of $21 \%$ of the ${ }^{118} \mathrm{MBT}$ and $18 \%$ of the inorganic ${ }^{118} \mathrm{Sn}$. In anoxic porewaters the observed degradations were somewhat weaker because $18 \%$ and $13 \%$ of the ${ }^{118}$ DBT were degraded in M2 and M1, respectively. However, the whole amount of spiked 
${ }^{118} \mathrm{DBT}$ in anoxic porewater M2 appeared to degrade directly to ${ }^{118} \mathrm{Sn}(18 \%)$ because no formation of ${ }^{118} \mathrm{MBT}$ was observed. A similar result was obtained in anoxic porewater M1, where the slight formation of ${ }^{118} \mathrm{MBT}$ was observed only after one day of incubation (6\%), whereas on the third day only an increase in inorganic ${ }^{118} \mathrm{Sn}$ was quantified (18\%). This suggests that in anoxic porewaters MBT degraded to inorganic tin almost immediately after it was formed, thus indicating that MBT degradation in anoxic conditions is much faster than the degradation of DBT to MBT and faster than the MBT degradation in oxic porewaters. Additionally, it is possible that a portion of DBT is directly degraded to inorganic tin. This clearly explains our finding that MBT never accumulates in the sediments where efficient TBT degradation occurs (M1-M4). The assumption of different DBT microbial degradation mechanisms in oxic and anoxic conditions is supported by the work of Bridou et al. [42] and Yonezawa et al. [43] where total TBT degradation to inorganic tin was demonstrated under anoxic conditions, whereas the formation of MBT as an intermediate product was not observed. Apart from the microbial degradation, the abiotic degradation of BuTs in porewater could also play a role; Peeters et al. [44] recently demonstrated great importance of abiotic DBT degradation during the incubation of landfill leachate, whereas the abiotic degradation of TBT was not observed in their study. Zeng et al. $[45,46]$ in their recent study showed that chemical species naturally present in anoxic sediments and porewater, such as reduced sulfur species $\left(\mathrm{HS}^{-}, \mathrm{Sn}^{2-}\right.$ ), dissolved organic matter and reactive mineral phases, induce abiotic degradation of pesticides. Organotin compounds could be also prone to such chemical degradation, since $\mathrm{Sn}-\mathrm{C}$ bond is susceptible to attack by both nucleophilic and electrophilic reagents [47].

The degradation of ${ }^{116} \mathrm{TPhT}$ was not observed in any incubated porewater after 3 days of incubation (Fig. 4c) under either oxic or anoxic conditions. This indicates that the first step is the limiting step in PhT degradation, the same as for BuTs. However, some degradation of ${ }^{116} \mathrm{DPhT}$ (5\%) and ${ }^{116} \mathrm{MPhT}$ (12\%), which were not the products of ${ }^{116} \mathrm{TPhT}$ degradation because they were already present in the spike solution $\left(t_{0}\right)$, was observed in oxic porewater M2 with the ${ }^{116} \mathrm{MPhT}$ degradation being approximately 2 times more rapid than the ${ }^{116} \mathrm{DPhT}$ degradation. In anoxic porewaters, only ${ }^{116} \mathrm{MPhT}(15 \%)$ degradation was observed in porewater M2 on the first day. Comparing the PhT and butyltin degradations, the observed ${ }^{116} \mathrm{DPhT}$ degradation was approximately 10 times slower than ${ }^{118}$ DBT degradation in oxic porewaters.

From the determined transformation yields, the degradation and formation rate constants were calculated following a firstorder kinetic model (Table 1). They show that in oxic porewaters DBT degradation is 3.3 times more rapid than TBT degradation, leading to the conclusion that the first debutylation step is the limiting step in the total TBT degradation. Because the DBT degradation rate is more rapid than its formation rate, DBT should never accumulate in surface sediments. Furthermore, the DBT degradation rate constants are approximately 3 times greater for oxic than for anoxic porewaters in both cores; meanwhile, they are similar for both oxic and anoxic porewaters, strongly suggesting that DBT degradation occurs at similar rates in different sediments. This observation clearly explains the equal proportions of DBT (20-30\%) that were observed throughout the entire depth of all investigated sediment cores. The degradation constant for PhTs could be calculated only for the inorganic ${ }^{116} \mathrm{Sn}$ formation in M2 oxic porewaters, and it was approximately 2.8 times lower than the formation of ${ }^{118} \mathrm{Sn}$ originating from ${ }^{118} \mathrm{DBT}$. This suggests that in oxic porewaters PhT degradation is slower than the degradation of BuTs. The available data on phenyltin degradation in sediments are very scarce and all based on the evaluation of degradation rates from the ratios between TPhT and the total PhTs [2]; thus, they do not provide any information about the degradation mechanism. Therefore, these are the first data on the PhT degradation routes and kinetics in porewaters.

The TBT degradation routes have been discussed many times in literature but with contrasting conclusions; some authors have demonstrated that TBT degradation occurs as a stepwise loss of one butyl group [24,28], whereas others have claimed that direct TBT degradation to MBT occurs $[17,18,48]$. The results of our study strongly suggest that the formation of MBT was the result of DBT debutylation and not of direct TBT degradation to MBT because the formation constants of ${ }^{117} \mathrm{MBT}$ (originated from ${ }^{117} \mathrm{TBT}$ ) and ${ }^{118} \mathrm{MBT}$ (originated from ${ }^{118} \mathrm{DBT}$ ) were similar. Furthermore, the similar ${ }^{117} \mathrm{Sn}$ and ${ }^{118} \mathrm{Sn}$ formation constants suggest that inorganic tin came from DBT, thus rejecting a possibility of direct TBT degradation to inorganic tin as the main degradation process.

On the basis of the degradation rate constants determined, the half-lives $\left(t_{1 / 2}\right)$ of TBT and DBT in porewaters were calculated. They were 9.2 days for TBT and $2.9 \pm 0.1$ days for DBT in porewaters under oxic conditions and $9.1 \pm 0.9$ days for DBT in porewaters under anoxic conditions. Because the most common half-lives of TBT in sediments reported in the literature range from 1 to 10 years $[1,12,24]$, our results demonstrate that once TBT is desorbed from the sediment to the porewater, its degradation occurs rather fast. Furthermore, the determined half-life of TBT in oxic porewater was similar or faster than those commonly reported for surface waters, which range from several days to weeks $[1,6]$. In the work of Rodriguez-Gonzales et al. [5] the same experimental design was used to study TBT transformations in oxic surface waters. Comparing the results of their work with those obtained in our study and considering similar incubation conditions (oxic conditions, absence of light), the rate of TBT degradation in porewater and surface water is comparable. However, the DBT degradation rate is up to ten times higher in oxic porewaters than in oxic surface waters.

With the aim of further interpretation of our results, the natural concentrations of BuTs in porewaters from two locations were determined (Fig. 5a and b). Location M2 (Fig. 5a) refers to the sediment where butyltin concentrations and TOC decreased with sediment depth (first group), while location M6 (Fig. 5b) refers to the sediment where they were constant with depth (second group). The butyltin concentrations in porewaters ranged from 0.2 to $7.8 \mathrm{ng}(\mathrm{Sn}) / \mathrm{l}$, and they were comparable to those determined in the overlying water [4] as well as to those few reported in the literature $[10,13]$. From the presented profiles the following can be observed: (i) the TBT concentrations in porewaters followed the same depth pattern as in sediments; (ii) DBT did not accumulate in porewaters at both locations, and its proportion was never higher than $30 \%$, the same as was observed for DBT behavior in sediments; and (iii) the butyltin concentrations were similar in both porewaters despite the concentration of BuTs in sediments being 5-25 times higher at location M6 than at M2, thus indicating that the concentration of bioavailable BuTs in porewater is not directly proportional to the concentration in the solid phase.

The distribution coefficients $(\mathrm{Kd})$ were calculated and are shown in Table 2. They are defined as the ratio between the butyltin concentrations in sediment and porewater, thus describing the sorption capacity of the particular sediment. The calculated Kd values (presented as log $\mathrm{Kd}(\mathrm{l} / \mathrm{kg})$ ) ranged from 4.05 to 5.09 for TBT, 4.52-4.81 for DBT and 3.30-4.85 for MBT, similar or higher than those reported in the literature $[10,11,13]$. The Kd values for TBT were generally higher for sediment M6, which had a higher TOC content (Table 2) and lower degradation efficiency (BDI $<1$ ), all of which support our previous discussion on the stronger TBT adsorption and consequently weaker TBT degradation in sediments with a higher TOC content. Therefore, in contaminated sediments rich in organic matter, less BuTs will be desorbed, and a higher persistence 
of toxic TBT can be expected than in sediments with lower organic matter content.

\section{Acknowledgments}

We thank Jelena Dautovic (TOC analyses), Maja Ivanic (granulometric analyses) and Niko Bacic (assistance in sampling). Financial support from the Croatian Science Foundation through the project IP-11-2013-7555 TRACESS is acknowledged. The work was performed in the framework of Croatian-French scientific collaboration supported by the Croatian and French Ministries of Science.

\section{References}

[1] I. Omae, Organotin antifouling paints and their alternatives, Appl. Organomet. Chem. 17 (2003) 81-105.

[2] A.X. Yi, K.M.Y. Leung, M.H.W. Lam, J.S. Lee, J.P. Giesy, Review of measured concentrations of triphenyltin compounds in marine ecosystems and meta-analysis of their risks to humans and the environment, Chemosphere 89 (2012) 1015-1025.

[3] A. Filipkowska, G. Kowalewska, B. Pavoni, L. Leczynski, Organotin compounds in surface sediments from seaports on the Gulf of Gdansk (southern Baltic coast), Environ. Monit. Assess. 182 (2011) 455-466.

[4] M. Furdek, M. Vahcic, J. Scancar, R. Milacic, G. Kniewald, N. Mikac, Organotin compounds in seawater and mussels Mytilus galloprovincialis along the Croatian Adriatic coast, Mar. Pollut. Bull. 64 (2012) 189-199.

[5] P. Rodriguez-Gonzalez, S. Bouchet, M. Monperrus, E. Tessier, D. Amouroux, In situ experiments for element species-specific environmental reactivity of tin and mercury compounds using isotopic tracers and multiple linear regression, Environ. Sci. Pollut. Res. 20 (2013) 1269-1280.

[6] A. Filipkowska, G. Kowalewska, B. Pavoni, Organotin compounds in surface sediments of the Southern Baltic coastal zone: a study on the main factors for their accumulation and degradation, Environ. Sci. Pollut. Res. 21 (2014) 2077-2087.

[7] G. Mailhot, M. Astruc, M. Bolte, Degradation of tributyltin chloride in water photoinduced by iron(III), Appl. Organometal. Chem. 13 (1999) 53-61.

8] G. Mailhot, M. Brand, M. Astruc, M. Bolte, Photoinduced degradation by iron(III): removal of triphenyltin chloride from water, Appl. Organometal. Chem. 16 (2002) 27-33.

[9] M. Hoch, Organotins in the environment-an overview, Appl. Geochem. 16 (2001) 719-743.

[10] M. Berg, C.G. Arnold, R.S. Müller, J. Mühlemann, R.P. Schwarzenbach, Sorption and desorption behavior of organotin compounds in sediment-pore water systems, Environ. Sci. Technol. 35 (2001) 3151-3157.

[11] E.D. Burton, I.R. Phillips, D.W. Hawker, Sorption and desorption behavior of tributyltin with natural sediments, Environ. Sci. Technol. 38 (2004) 6694-6700.

[12] A.C. Almeida, A.L.R. Wagener, C.B. Maia, N. Miekeley, Speciation of organotin compounds in sediment cores from Guanabara Bay, Rio de Janeiro (Brazil) by gas chromatography-pulsed flame photometric detection, Appl. Organomet. Chem. 18 (2004) 694-704.

[13] L. Viglino, E. Pelletier, R. St-Louis, Highly persistent butyltins in northern marine sediments: a long-term threat for the Saguenay fjord (Canada), Environ. Toxicol. Chem. 23 (2004) 2673-2681.

[14] M. Hoch. J. Alonso-Azcarate, M. Lischick, Assessment of adsorption behavior of dibutyltin (DBT) to clay-rich sediments in comparison to the highly toxic tributyltin (TBT), Environ. Pollut. 123 (2003) 217-227.

[15] K. Hamer, V. Karius, Tributyltin release from harbour sediments-modelling the influence of sedimentation, bio-irrigation and diffusion using data from Bremerhaven, Mar. Pollut. Bull. 50 (2005) 980-992.

[16] K. Fent, Ecotoxicology of organotin compounds, Crit. Rev. Toxicol. 26 (1996) $1-117$.

17] D. Adelman, K.R. Hinga, M.E.Q. Pilson, Biogeochemistry of butyltins in an enclosed marine ecosystem, Environ. Sci. Technol. 24 (1990) 1027-1032.

[18] P.F. Seligman, R.J. Maquire, R.F. Lee, K.R. Hinga, A.O. Valkirs, P.M. Stang, Persistence and fate of tributyltin in aquatic ecosystem, in: M.A. Champ, P.F. Seligman (Eds.), Organotin-Environmental Fate and Effects, Chapman and Hall, London, 1996, pp. 429-457.

[19] H. Ma, S. Dai, G. Huang, Distribution of tributyltin chloride in laboratory simulated estuarine microcosms, Water Res. 34 (2000) 2829-2841.

[20] E. Tessier, D. Amouroux, A. Morin, L. Christian, E. Thybaud, E. Vindimiam, O.F.X. Donard, Tributyltin biotic degradation rates and pathways in different compartments of a freshwater model ecosystem, Sci. Total Environ. 388 (2007) 214-233.
[21] A. Sakultantimetha, H.E. Keenan, T.K. Beattie, TJ. Aspray, S. Bangkedphol, A. Songsasen, Acceleration of tributyltin biodegradation by sediment microorganisms under optimized environmental conditions, Int. Biodeterior. Biodegrad. 64 (2010) 467-473.

[22] S. Brosillon, C. Bancon-Montigny, J. Mendret, Study of photocatalytic degradation of tributyltin, dibutylin and monobutyltin in water and marine sediments, Chemosphere 109 (2014) 173-179.

[23] P.H. Dowson, J.M. Bubb, J.N. Lester, Depositional profiles and relationships between organotin compounds in freshwater and estuarine sediment cores, Environ. Monitor. Assess. 28 (1993) 145-160.

[24] P.M. Sarradin, Y. Lapaquellerie, A. Astruc, C. Latouche, M. Astruc, Long term behaviour and degradation kinetics of tributyltin in a marina sediment, Sci. Total Environ. 170 (1995) 59-70.

[25] M.D. Scrimshaw, R. Wahlen, T. Catterick, J.N. Lester, Butyltin compounds in a sediment core from the old Tilbury basin London, UK, Mar. Pollut. Bull. 50 (2005) 1500-1507.

[26] M. Hoch, D. Schwesig, Parameters controlling the partitioning of tributyltin (TBT) in aquatic systems, Appl. Geochem. 19 (2004) 323-334.

[27] S. Diez, E. Jover, J. Albaiges, J.M. Bayona, Occurence and degradation of butyltins and wastewater marker compounds in sediments from Barcelona harbor, Spain, Environ. Int. 32 (2006) 858-865.

[28] E.D. Burton, I.R. Phillips, D.W. Hawker, In-situ partitioning of butyltin compounds in estuarine sediments, Chemosphere 59 (2005) 585-592.

[29] T. Milivojevič Nemanič, R. Milačič, J. ك̌čančar, A survey of organotin compounds in the Northern Adriatic Sea, Water Air Soil Pollut. 196 (2009) 211-224.

[30] P. Rodriguez-Gonzalez, M. Monperrus, J.I. Garcia Alonso, D. Amouroux, O.F.X. Donard, Comparison of different numerical approaches for multiple spiking species-specific isotope dilution analysis exemplified by the determination of butyltin species in sediments, J. Anal. Am. Spectrom. 22 (2007) 1373-1382.

[31] J. Germán Rodríguez, O. Solaun, J. Larreta, M.J. Belzunce Segarra, J. Franco, J.I García Alonso, C. Sariego, V. Valencia, A. Borja, Baseline of butyltin pollution in coastal sediments within the Basque Country (northern Spain), in 2007-2008, Mar. Pollut. Bull. 60 (2010) 139-145.

[32] C.R. de Oliveira, D. dos Santos, L.A. dos Santos Madureira, M.R.R. de Marchi, Speciation of butyltin derivatives in surface sediments of three southern Brazilian harbors, J. Hazard. Mater. 181 (2010) 851-856.

[33] P.H. Dowson, J.M. Bubb, T.P. Williams, J.N. Lester, Degradation of tributyltin in freshwater and estuarine marina sediments, Water Sci. Technol. 28 (1993) 133-137.

[34] J. Landmeyer, T. Tanner, B. Watt, Biotransformation of tributyltin to tin in freshwater river-bed sediments contaminated by an organotin release, Environ. Sci. Technol. 38 (2004) 4106-4112.

[35] S. Diez, M. Abalos, J.M. Bayona, Organotin contamination in sediments from the Western Mediterranean enclosures following 10 years of TBT regulation, Water Res. 36 (2002) 905-918.

[36] J. Poerschmann, F.D. Kopinke, J. Pawliszyn, Solid phase microextraction to study the sorption of organotin compounds onto particulate and dissolved humic organic matter, Environ. Sci. Technol. 31 (1997) 3629-3636.

[37] B.N. Bhosle, A. Garg, R. Harji, S. Jadhav, S.S. Sawant, V. Krishnamurthy, C. Anil, Butyltins in the sediments of Kochi and Mumbai harbours west coast of India, Environ. Int. 32 (2006) 252-258.

[38] C.J. Buggy, J.M. Tobin, Seasonal and spatial distributions of tributyltin in surface sediment of the Tolka Estuary, Dublin, Ireland, Environ. Pollut. 143 (2006) 294-303.

[39] M.A. Wetzel, A. Winterscheid, D.S. Wahrendorf, Baseline of the butyltin distribution in surface sediments $(0-20 \mathrm{~cm})$ of the Elbe estuary (Germany, 2011), Mar. Pollut. Bull. 77 (2013) 418-423.

[40] D.J. Burdige, Geochemistry of Marine Sediments, Princeton University Press, New Jersey, 2006.

[41] L.M. Mayer, Relations between mineral surface and organic-carbon concentrations in soils and sediments, Chem. Geol. 114 (1994) 347-363.

[42] R. Bridou, P. Rodriguez-Gonzàlez, M. Monperrus, P. Navarro, E. Tessier, P. Caumette, D. Amouroux, R. Guyoneaud, (Butyl) tins degradation and methylation at environmental levels by strains of different 3 bacterial functional groups under oxic and anoxic conditions (2015) (in press).

[43] Y. Yonezawa, M. Fukui, T. Yoshida, A. Ochi, T. Tanaka, Y. Noguti, T. Kowata, Y. Sato, S. Masunaga, Y. Urushigawa, Degradation of tri- $n$-butyltin in Ise Bay sediment, Chemosphere 29 (1994) 1349-1356.

[44] K. Peeters, T. Zuliani, J. Ščančar, R. Milačič, The use of isotopically enriched tin tracers to follow the transformation of organotin compounds in landfill leachate, Water Res. 53 (2014) 297-309.

[45] T. Zeng, Y.P. Chin, W.A. Arnold, Potential for abiotic reduction of pesticides in prairie pothole porewaters, Environ. Sci. Technol. 46 (2012) 3177-3187.

[46] T. Zeng, K. Ziegelgruber, Y.P. Chin, W.A. Arnold, Pesticide processing potential in prairie pothole porewaters, Environ. Sci. Technol. 45 (2011) 6814-6822.

[47] S.J. Blunden, L.A. Hobbs, P.J. Smith, The environmental chemistry of organotin compound, in: H.J.M. Bowen, S.J. Blunden (Eds.), Environmental Chemistry. Volume 3: A Review of the Literature Published Up to End 1982, Royal Society of Chemistry, London, 1984, pp. 49-78.

[48] P.H. Dowson, J.M. Bubb, J.N. Lester, Persistence and degradation pathways of tributyltin in freshwater and estuarine sediments, Estuarine Coast Shelf Sci. 42 (1996) 551-562. 